\title{
A CONSTRUÇÃO DO ETHOS EM CRÔNICAS DE MANUEL BANDEIRA
}

\author{
THE CONSTRUCTION OF ETHOS IN \\ MANUEL BANDEIRA'S CHRONICLES
}

\author{
JAURANICE RODRIGUES CAVALCANTI ${ }^{1}$
}

\begin{abstract}
RESUMO: Nosso objetivo neste trabalho é discutir o conceito de ethos explorando seu aspecto de construção por parte do intérprete. Trata-se de parte de uma pesquisa mais ampla que investiga as crônicas de Manuel Bandeira levando em conta as reflexões da Análise do Discurso francesa (AD) sobre o campo literário, em especial o quadro teórico-metodológico proposto por Maingueneau (2006a). Aqui, apoiamo-nos nas reflexões do analista (2000, 2006a, 2016) sobre ethos, a teoria que elabora a partir da noção de ethos retórico. Maingueneau parte do princípio de que os textos escritos também podem ser associados a um tom, a uma voz que remete à figura do locutor, à imagem que $o$ intérprete dele constrói. $\mathrm{O}$ analista (2006a) elenca algumas dificuldades ligadas à noção: a primeira advém da constatação de que o público constrói determinadas representações do locutor antes mesmo que ele enuncie, o que faz com que proponha uma distinção entre ethos discursivo e ethos prédiscursivo. Uma segunda ordem de problemas provém do fato de que, quando da elaboração do ethos, fatores diversos interagem, como a afetividade do intérprete. Baseados nessa teoria, analisamos um conjunto de dados encontrados em crônicas de Manuel Bandeira. Trata-se de um material que permite a observação de aspectos ligados à construção do ethos por parte do intérprete, aos índices em que se apoia para construí-lo. A análise aponta os vocábulos e expressões com função descritivo-avaliativa como lugar privilegiado de atribuição de um ethos franco, digno, um ethos de homem de bem.

Palavras-chave: ethos discursivo; crônica; Manuel Bandeira.
\end{abstract}

ABSTRACT: The aim of this article is to discuss the ethos concept researching its construction aspect done by the reader. It is part of a larger research that studies the Manuel Bandeira's chronicles taking to account the Discourse Analysis about the literary field, specially the theoretical framework proposed by Maingueneau (2006a). In the present, we are supported in analyst considerations about ethos, the theory he proposes from the rhetorical ethos. Maingueneau considers that written texts also can be associated to a voice that points out to the speaker, to the image constructed by the interpreter. The analyst enumerated some problems related to the notion: the first one derives from the consideration that the public constructs some representations of the speaker before he talks, consideration that cause the distinction between discursive ethos from pre-ethos. The second one comes from the fact that, during ethos construction, different points interact, like the interpreter affectivity. Based in this theory, we consider a set of data located in Manuel Bandeira's chronicles. The analysis shows the words and description-evaluation expressions as the privileged locus of assignment a honest ethos, an ethos of a good man.

Keywords: discursive ethos; chronicle; Manuel Bandeira.

${ }^{1}$ Universidade Federal do Triângulo Mineiro, Uberaba, MG, Brasil. jrodriguescavalcanti@terra. $\underline{\text { com.br }}$ 


\section{INTRODUÇÃO}

Neste artigo, procuramos fazer um estudo sobre o ethos tomando por objeto de análise crônicas de Manuel Bandeira. Trata-se de parte de uma pesquisa que investiga a prosa desse autor, investigação fundamentada nas reflexões da Análise do Discurso francesa sobre o campo literário, em especial o quadro teórico-metodológico proposto por Maingueneau (2006a). Na primeira seção, apresentamos a teoria que Maingueneau desenvolveu sobre ethos discursivo, mostrando que o analista considera ser este o resultado de um processo que envolve o ethos pré-discursivo, o ethos mostrado e o ethos dito.

$\mathrm{Na}$ seção seguinte, discorremos sobre o ethos pré-discursivo e também acerca do conceito imagem de autor proposto por Maingueneau (2010). Antes das análises, apresentamos algumas informações sobre o corpus selecionado para a pesquisa, a saber, trechos de onze crônicas de Manuel Bandeira. Segue, então, a seção com as análises e, por fim, as considerações finais do estudo.

\section{O ETHOS DISCURSIVO}

Maingueneau (2000, 2006a, 2016) recupera o conceito de ethos da Retórica dando a ele uma concepção discursiva. Nas primeiras pesquisas, o autor (2000), destaca a importância dada por Bakhtin ao tom dos discursos, a seu modo de enunciação. De acordo com o analista, o pensador russo relaciona a voz que emerge dos enunciados ao locutor e à figura de seu parceiro, aspecto que Maingueneau explora em trabalhos posteriores.

Como é traço de suas reflexões, Maingueneau vai construindo, (re)elaborando os conceitos à medida que realiza suas pesquisas, a partir de problemas colocados pelos objetos de análise. Em relação ao ethos, podemos observar que precisa e refina o conceito em "Problemas de ethos" (2006b) e "Retorno crítico sobre o ethos" (2016), nos quais discorre acerca de aspectos cruciais ligados à noção.

Como mostramos (Cavalcanti; Rezende, 2017), Maingueneau (2006b) elenca algumas dificuldades ligadas à noção após fazer considerações sobre o ethos retórico. A primeira advém da constatação de que o público constrói determinadas representações do locutor antes mesmo que ele enuncie, o que faz com que o analista proponha uma distinção entre ethos discursivo e ethos pré-discursivo. Mesmo em momentos ou tipos de discurso em que não se espera que o destinatário disponha de representações prévias do locutor, Maingueneau (2006a) observa que o simples fato de um texto pertencer a um gênero de discurso ou a um certo posicionamento ideológico permite que se criem expectativas em termos de ethos.

Uma segunda ordem de problemas provém do fato de que, quando da elaboração do ethos, fatores diversos interagem. Nas palavras de Maingueneau

Os índices sobre os quais se apoia o intérprete vão desde a escolha do registro da língua e das palavras até o planejamento textual, passando pelo ritmo e pela modulação. O ethos se elabora, assim, por meio de uma percepção complexa que mobiliza a afetividade do intérprete, que tira suas informações do material linguístico e do ambiente (2006b, p. 57). 
Além das duas ordens apontadas, Maingueneau (2006b) acrescenta que a noção de ethos, conforme seja considerada do ponto de vista do locutor ou do destinatário, remete a coisas bem diferentes, isto é, "o ethos visado não é necessariamente o ethos produzido" (2006b, p. 58). Por exemplo, um professor que quer construir de si a imagem de sério pode ser percebido como monótono, ou o indivíduo que quer passar a imagem de aberto e simpático pode ser percebido como demagogo: "os fracassos, em matéria de ethos, são moeda corrente" (2006b, p.58), afirma o analista. Esse aspecto é desenvolvido em "Retorno crítico sobre o ethos" (2016).

Maingueneau (2006b) conclui que a noção de ethos não tem um valor unívoco, mesmo em Aristóteles recebe tratamentos diversos na Política e na Retórica. No entanto, limitando-se à última obra, destaca algumas ideias com as quais afirma ser possível concordar. São elas:

i) o ethos é uma noção discursiva, constitui-se por meio do discurso, não se trata de uma imagem do locutor exterior à fala;

ii) o ethos é um processo interativo, de influência sobre o outro;

iii) o ethos é uma noção híbrida, não pode ser apreendido fora de uma situação de comunicação precisa.

Levando em conta as ideias destacadas, Maingueneau (2006b) apresenta a noção de ethos discursivo por ele elaborada. Antes disso, ressalta que seu interesse recai sobre textos produzidos em gêneros discursivos instituídos, aqueles nos quais os parceiros da interação ocupam papéis pré-estabelecidos, seguindo "rotinas" mais ou menos precisas no desenvolvimento da organização textual. Não é isso que ocorre nos gêneros discursivos conversacionais, em que os lugares dos parceiros podem ser negociados e o desenvolvimento do texto não obedece a restrições macroestruturais.

Dessa forma, o objeto de interesse de Maingueneau demanda a reelaboração do conceito de ethos retórico na medida em que esse último é relacionado apenas a textos orais. $\mathrm{O}$ analista parte do princípio de que os textos escritos também podem ser associados a um tom, a uma voz que remete à figura do locutor, à imagem que o destinatário dele constrói. Outro ponto destacado por Maingueneau é que sua perspectiva ultrapassa o quadro da argumentação, porque "além da persuasão pelos argumentos, a noção de ethos permite refletir sobre o processo mais geral da adesão dos sujeitos a um certo posicionamento" (2006b, p. 61, grifo do autor).

A reflexão sobre o processo de adesão implica considerar a figura de um fiador, aquele que atesta o que diz por meio de seu tom. Maingueneau ressalta que o ethos discursivo recobre, além do aspecto verbal, "o conjunto das determinações físicas e psíquicas associadas ao "fiador' pelas representações sociais" (2006b, p. 62). Assim, o destinatário atribui ao fiador um "caráter" e uma "corporalidade", traços que identifica apoiando-se em um conjunto de representações avaliadas de 
forma positiva ou negativa e de estereótipos "que a enunciação contribui para reforçar ou transformar" (2006b, p. 62).

Além disso, o analista afirma que a incorporação do destinatário ultrapassa a simples identificação ao fiador, pois implica um "mundo ético" do qual essa voz fiadora faz parte, ao qual ela dá acesso. Esse mundo ético, que é ativado por meio da leitura, é um estereótipo cultural que reúne um certo número de situações estereotípicas associadas a determinados comportamentos. Os textos publicitários são um bom exemplo: o fiador aparece associado ao mundo dos executivos, das celebridades etc., capaz de dar acesso a esses mundos.

O termo "incorporação", proposto por Maingueneau, designa "a maneira pela qual o destinatário em posição de intérprete - ouvinte ou leitor - se apropria desse ethos" (2006b, p. 62). Assim, o ethos de um discurso decorre da interação de diversos fatores: ethos pré-discursivo, ethos discursivo (mostrado), ethos dito. Essa última dimensão pode ser exemplificada por fragmentos de textos em que o locutor evoca sua própria enunciação diretamente ("é um amigo que lhes fala") ou indiretamente, por meio de alusões a outras cenas de fala.

Para exemplificar a noção, Maingueneau analisa a propaganda de uma máquina fotográfica (Canon), que apresenta o seguinte enunciado "Mostre do que você é capaz". Embora o fiador não apareça explicitado (o texto é construído na terceira pessoa), ele é mostrado por sua maneira de dizer, por seu ethos, que "convida" o leitor a fazer parte de "um mundo mítico viril de matriz tecnológica e de espírito de aventura" (2006b, p. 63). Maingueneau lembra que o discurso publicitário contemporâneo mantém um laço privilegiado com o ethos, uma vez que procura persuadir os consumidores associando os produtos anunciados a uma maneira de habitar o mundo.

Outra observação interessante feita pelo analista: é preciso considerar a distância entre o ethos que um dado texto pretende que seja elaborado por seus destinatários e o ethos que esses efetivamente elaboram em função de sua identidade ou das situações nas quais se encontram. Vê-se, aqui, que a adesão ao ethos não é automática ou garantida, mas depende de o destinatário se identificar com o tom do fiador, com o mundo ético habitado por ele. Levando em conta o texto publicitário apresentado por Maingueneau, pode ocorrer de consumidores elaborarem um ethos agressivo e violento (e não viril e convidativo), não incorporando a voz fiadora da propaganda, não se identificando com ela. Nesse caso, o efeito de incorporação não se produziria.

Em "Retorno crítico sobre o ethos" (2016), Maingueneau amplia as reflexões sobre a dimensão interativa do ethos, sobre o efeito de incorporação. Começa afirmando que a operacionalização do conceito levanta muitas dificuldades, uma vez que seu conteúdo é muito variável ou mesmo desigual: "é, por exemplo, a questão de ethos 'de professor', 'de esposa', 'de político', 'de competência', ethos de 'calma', 'comunista', 'rural', 'profético', etc." (Maingueneau, 2016, p. 13). De acordo com o analista, esse fato é compreensível se levarmos em conta que o conteúdo dado ao ethos depende em grande medida dos tipos ou gêneros de discurso estudados. Suas pesquisas, por exemplo, tomaram por objeto de análise textos religiosos, literários e publicitários nos quais a concepção de ethos, 
elaborada em termos de incorporação e de sua dimensão psicológica, mostrou-se produtiva.

No entanto, Maingueneau considera que outros tipos de texto exigem que o conceito seja retomado e expandido, o que faz nesse artigo. Propõe, assim, atribuir ao ethos três dimensões, a saber, categórica, experiencial e ideológica, que interagem fortemente e são mais ou menos relevantes de acordo com os textos considerados. A dimensão categórica concerne coisas muito diferentes: pode ser papéis discursivos ou estatutos extradiscursivos. Os primeiros são relacionados a atividades de fala (animador, contador de histórias, pregador); os últimos podem ser de natureza variada (pai de família, funcionário, médico, americano, solteiro etc.). A dimensão experiencial do ethos diz respeito às caracterizações sóciopsicológicas estereotipadas, associadas à noção de incorporação e de mundo ético. Trata-se, portanto, de uma dimensão já explorada pelo analista em seus trabalhos. Já a dimensão ideológica se refere a posicionamentos no interior de um dado campo discursivo: feminista, de esquerda, de direita, em um campo político; parnasiano ou simbolista, em um campo literário etc.

Maingueneau afirma que a lista de predicados para caracterizar um ethos é aberta. Mas os analistas filtram os elementos a considerar nessa lista em função do gênero e do tipo de discurso. Dessa forma

quando se trata de um gênero político eleitoral, o analista vai privilegiar principalmente os predicados que pertencem ao posicionamento ideológico (de direita, pró-europeu, anarquista) e os predicados psicológicos pertinentes (competência, autoridade, honestidade, coragem) (Maingueneau, 2016, p. 15).

Na sequência, Maingueneau tece considerações acerca da identificação do ethos, que expandem as reflexões realizadas em artigos anteriores. Para o analista, a maioria dos trabalhos sobre ethos é feita como se sua identificação fosse evidente, o que não ocorre em alguns tipos de textos, como aqueles selecionados para compor o corpus desse trabalho do analista - textos retirados de um site de namoro. Aqui Maingueneau conceitua o ethos dito como aquilo que o locutor diz de si mesmo em contraste com o ethos mostrado, isto é, como aquilo que o locutor mostra em sua maneira de enunciar.

O exame desse material permite que Maingueneau apreenda diferentes estratégias na relação entre o ethos dito e o ethos mostrado. Para cada uma delas, o analista levanta hipóteses sobre a construção do ethos, mostrando como esse processo varia de acordo com as decisões interpretativas do destinatário. Nas breves análises que elabora, explora o apagamento do ethos dito e do ethos mostrado e também a convergência entre esses dois ethe, apontando, assim, diferentes estratégias de construção do ethos.

\section{SOBRE O CORPUS}

Quem decide estudar a produção de Manuel Bandeira em prosa se depara com um vasto material que inclui crônicas, estudos críticos, relato autobiográfico e traduções. Em relação ao primeiro gênero, são inúmeros os textos, muitos até 
pouco tempo inéditos, publicados em órgãos de imprensa de todo o país. Na cronologia de sua vida e obra, que escreve para o volume Poesia completa e Prosa publicada pela Nova Aguilar, Bandeira faz referência a três livros que reúnem parte das crônicas: As crônicas da província do Brasil, publicado em 1936 pela Civilização Brasileira, com textos escritos para os jornais A Província do Recife, O Diário Nacional, de São Paulo e O Jornal, do Rio de Janeiro, Flauta de Papel, publicado em 1957 pela editora Alvorada e Andorinha Andorinha, publicado em 1966, data em que o poeta completa 80 anos e recebe homenagens, sendo uma delas a publicação do livro organizado pelo amigo Carlos Drummond de Andrade. Sobre esses dois últimos, não aparecem informações a respeito dos periódicos em que foram veiculadas as crônicas.

Em seu Itinerário de Pasárgada, Bandeira refere-se às crônicas em poucos momentos. Um deles é quando, em tom queixoso, relata que teve publicadas em livro As crônicas da província do Brasil, mas não seus poemas: "editou-me a Civilização Brasileira um livro de prosa, não ousaria editar um de versos" (1985, p. 84). Sobre esse livro é importante destacar sua reedição pela CosacNaify, com organização de Júlio Castañon Guimarães, que oferece ao leitor informações cruciais, como a data e o veículo de comunicação no qual as crônicas foram veiculadas, informações ausentes nos livros Flauta de Papel e Andorinha Andorinha.

Além de organizar a reedição de As crônicas da província do Brasil, Guimarães é responsável pela organização de uma série de crônicas de Manuel Bandeira escritas para a imprensa no período de 1920 a 1944, inéditas em livro: as Crônicas inéditas I e as Crônicas inéditas 2, também editadas pela CosacNaify. Nelas o leitor encontra, da mesma forma, as datas e os jornais para os quais foram escritos os textos, dados importantes para a atribuição de sentidos às crônicas.

Para este artigo, valemo-nos de textos publicados nos livros acima citados. Retiramos fragmentos de onze crônicas e esboçamos uma breve análise de cada um. Além disso, organizamos um quadro contendo mais exemplos de descrições avaliativas, que corroboram os predicados do ethos encontrados nas análises.

\section{ETHOS PRÉ-DISCURSIVO E IMAGEM DE AUTOR}

Iniciamos nossa análise discorrendo sobre o ethos pré-discursivo e seu papel na construção do ethos efetivo. Como se trata de textos produzidos por um nome que se destaca na memória coletiva de nossa sociedade, é importante levar em conta a imagem que o leitor tem desse nome. O conceito imagem de autor proposto por Maingueneau (2010) refere-se à acepção de autor como correlato de uma obra (um auctor), que responde "por um agrupamento de textos referidos a uma entidade que é identificável, que até pertence ao Thesaurus literário, quando alcança notoriedade" (2010, p. 142).

Para Maingueneau (2010), podem-se distinguir duas zonas principais da produção de sinais que contribuem para a construção de uma imagem de autor, a saber, uma zona em torno do ator e uma em torno do texto. Em relação à primeira, o analista afirma que é muito difícil separar a instância da pessoa da instância do 
escritor, retomando reflexões sobre o nó borromeano desenvolvidas em $O$ discurso literário. Assim, tanto uma como outra instância são fonte de produção de signos: o escritor, por meio dos textos que escreve, das entrevistas que concede etc.; e a pessoa, que mantém relações variáveis com o escritor e também com o inscritor.

Em relação aos elementos que giram em torno do texto, Maingueneau aponta, entre outros, os planos da personagem e da cenografia. A "contaminação" entre o autor do texto e suas personagens (ou uma delas) contribui para formar uma imagem de autor. Já a cenografia diz respeito à cena construída pelo texto, ao mundo configurado por ele. O público constrói uma imagem de autor levando em conta a apresentação do texto, a cena escolhida para materializá-lo.

Ao nome Manuel Bandeira associa-se uma imagem de autor construída por sinais provenientes tanto do autor como do texto. É comum relacionar o poeta à doença que o acometeu ainda jovem, à instância da pessoa, mas não devemos esquecer que essa se encontra imbricada à instância do escritor, aos textos que escreve, e à instância do inscritor, a um estilo bandeiriano. Também se deve levar em conta aquilo que provém dos textos, o que, no caso de Bandeira, pode ser pensado em termos de identificação do escritor à voz que enuncia em "Vou-me embora pra Pasárgada" e em outros poemas que tratam da "vida que podia ter sido e que não foi".

Trata-se de uma imagem de autor que exerce um importante papel na construção do ethos pré-discursivo, na elaboração de representações do ethos do locutor dos textos, mesmo que esses não sejam poemas, parte da obra de Bandeira mais conhecida do público. No entanto, é importante lembrar que, ao contrário do que se poderia esperar, isto é, uma voz "doente", abafada, enunciando que é preciso se evadir para Pasárgada a fim de encontrar a saúde e a felicidade, da leitura do poema emerge uma voz firme, franca e segura.

Vejamos como o conceito de ethos discursivo pode ser operacionalizado na leitura das crônicas. Separamos os textos em três grupos, a saber, aquele em que o ethos dito aparece explicitado, as crônicas que discorrem acerca de lugares visitados pelo cronista e, por fim, os que contêm comentários sobre conhecidos e pessoas amigas.

\section{ANÁLISE DO CORPUS}

\subsection{Falando de si}

São poucas as crônicas em que podemos encontrar trechos nos quais o autor fala de si, atribuindo-se traços físicos. O trecho que transcrevemos abaixo figura na crônica Minha mãe, publicada no livro Flauta de papel, reunião de textos feita pelo próprio Bandeira em 1957.

(1) Sempre me acharam muito parecido com minha mãe. Só no nariz diferíamos. A semelhança estava sobretudo nos olhos e na boca. Saí míope como ela, dentuço como ela. Há dentuços simpáticos e dentuços antipáticos. Muito tenho meditado sobre esse problema da antipatia de certos dentuços. Creio ter aprendido com minha mãe que o dentuço deve ser rasgado para não se 
tornar antipático. O dentuço que não ri para que não se perceba que ele é dentuço está perdido. Aliás, de um modo geral, a boca amável é a boca em que se vê claro. Era o caso de minha mãe: tinha o coração, já não digo na boca mas nos dentes, e estes eram fortes e brancos, alegres, sem recalques: anunciavam-na. Moralmente julgo ser muito diferente dela, mas fisicamente sinto-me cem por cento dela, que digo? Sinto-a dentro de mim, atrás de meus dentes e de meus olhos. Moralmente sou mais de meu pai, e alguma coisa de meu avô, pai de minha mãe. Sinto meu avô materno nos meus cabelos, sinto-o em certos meus movimentos de cordura. Naturalmente essas coisas vieram-me através de minha mãe. Minha mãe transmitiu-me traços de meu avô que, no entanto, não estavam nela. Que grande mistério que é a vida! Minha mãe era espontânea, sabia o que queria, não era nada tímida: ótimas qualidades que não herdei. (...) (Minha mãe, Bandeira, M., 2014, p. 40).

Embora fale da mãe morta, o tom não é triste ou melancólico, mas sim saudoso e respeitoso. Não se trata de uma mera descrição, um retrato da mãe, e daquele que o faz: a seleção das palavras e sua combinação (dentuço rasgado, os dentes anunciavam-na) dão ao trecho uma força que conquista o intérprete, leva-o a incorporar a voz que enuncia, a percebê-la como amiga e confiável. Observe-se o emprego de movimentos de cordura que permite associar uma corporalidade à voz, a saber, um homem elegante, distinto.

Na leitura do fragmento, é possível apreender o ethos dito a partir dos traços que o autor atribui a si (dentuço, míope) e aqueles que atribui à mãe e diz dela não ter herdado (decidida, extrovertida, espontânea). Como vimos, além do ethos dito, entra na elaboração do ethos efetivo o ethos pré-discursivo, a representação que o intérprete dispõe do autor antes que enuncie. Podemos dizer que uma antecipação em termos de doença e tristeza não é confirmada, o que ocorre na grande maioria das crônicas que selecionamos para análise. Dessa forma, o ethos efetivo é carinhoso, respeitoso e digno.

\subsection{Falando de lugares e pessoas}

Manuel Bandeira, como ele próprio relata em suas crônicas e em seu Itinerário de Pasárgada, desejava ser arquiteto, chegou a se matricular na Escola Politécnica de São Paulo. Era profundo conhecedor de arquitetura e urbanismo, o que explica o grande número de crônicas que tematiza cidades, igrejas, ruas e praças. Como modernista, empenhou-se, assim como Mario de Andrade, Oswald de Andrade, Tarsila do Amaral e outros, a "descobrir" o Brasil, a falar de suas riquezas, de seu povo, o que leva o escritor a fazer viagens pelo país (Minas Gerais, Pará, Bahia, Maranhão etc.). Vejamos o fragmento de uma crônica que foi veiculada em um número especial de O jornal, de Minas Gerais, em 1929, e depois publicada no livro Crônicas da província do Brasil, em 1937.

(2) Ao Aleijadinho só agora se começa a fazer justiça. A sua obra foi a flor extrema do luxo de um século de mineração. São Francisco de Assis de Ouro Preto é a obra de arte mais comovente do Brasil. Ali, tanto no interior como na frontaria e nas arcadas dos lados, está marcado o mais generoso esforço de criação do gênio mestiço da nossa gente: arte de uma saúde, de uma robustez, de uma dignidade a que nenhum outro artista atingiu entre nós ( $\mathrm{O}$ aleijadinho, Bandeira, 2006, p. 24). 
Discorrendo sobre Ouro Preto e a arte de Aleijadinho, o cronista os apresenta afirmando ter sido o artista injustiçado até então; trata-se, assim, de um nome que é preciso conhecer e valorizar, parte do projeto modernista de conhecimento de nossa gente, que pode ser reconhecido em crônicas como essa. A expressão que descreve a obra São Francisco de Assis de Ouro Preto não poderia ser mais significativa: $a$ obra de arte mais comovente do Brasil. O adjetivo comovente remete a uma voz que avalia a obra não com os olhos de um crítico, mas com o coração e a alma. Isso não significa que a avaliação se reduza a comentários sentimentaloides, o que pode ser atestado pelo último trecho do fragmento: à arte de Aleijadinho são atribuídos traços singulares, que surpreendem o leitor, a obra tem saúde, robustez e dignidade. Tal avaliação é feita em um tom firme e seguro, não há dúvidas sobre a grandeza do artista. Ressalte-se a expressão o mais generoso esforço de criação que alude de forma bastante expressiva a condição física do artista de Ouro Preto, como ele deveria superá-la para criar.

(3) A mania do neocolonial está se apoderando de todo o Brasil. Seria bom que nossos amadores de estilo dessem um pulo à Bahia para sentirem e apreenderem a razão, a força, a dignidade daqueles velhos solares ou dos altos sobradões dos bairros comerciais. Para ver se dariam depois outro rumo a estas tentativas de arte brasileira, que, positivamente, enveredam por caminho errado aqui no Sul, fazendo bonitinho, engraçadinho, enfeitadinho, quando o espírito das velhas casas brasileiras era bem o contrário disso, caracterizando-se antes pelo ar severo, recatado, verdadeiramente senhoril (Bahia, Bandeira, 2006, p. 43).

Aqui, o cronista lança mão, mais uma vez, de vocábulos "fortes" para descrever os casarões da Bahia, apontando-os como exemplo do que deveria ser seguido em matéria de construção. Para lá deveriam ir os "amadores de estilo" a fim de sentir e apreender "a razão, a força, a dignidade daqueles velhos solares ou dos altos sobradões dos bairros comerciais". As tentativas de arte brasileira são alvo de crítica irônica que se mostra pelo uso da sequência em diminutivos "fazendo bonitinho, engraçadinho, enfeitadinho". O espírito das casas da Bahia seria o contrário, isto é, forte, de "ar severo, recatado, verdadeiramente senhoril". O ethos mostrado está em conformidade com esse espírito: é uma voz forte e vigorosa, que inspira respeito.

(4) Olinda, São Salvador e Ouro Preto deveriam constituir pontos de peregrinação obrigatória para todo brasileiro que tenha o gosto de nossa história social e artística do nosso passado. Pelo fato de haverem sido os núcleos densos da vida colonial em épocas de prosperidade e riqueza, elas fixaram mais do que outras cidades do país o caráter da vida brasileira nos séculos XVII e XVIII. (...) Essa tradição é que cumpre zelar. Não permitir que seus templos se arruínem, como está acontecendo agora com a deliciosa capelinha do padre Faria, contemporânea dos primeiros descobrimentos de ouro. Sobretudo não consentir nas restaurações depredadoras do velho caráter de seus monumentos. A isso seria mil vezes de preferir a ruína, que destrói a matéria mas respeita a alma (Em defesa de Ouro Preto. Bandeira, 2008, p. 318).

São muitas as crônicas em que Bandeira lamenta aquilo que os projetos de restauração provocavam, a saber, a descaracterização de locais históricos, sua "modernização". Nesse fragmento, o autor volta a falar de cidades histórias, afirmando que elas deveriam ser conhecidas pelos brasileiros, destacando seu 
papel, o de fixar "o caráter da vida brasileira nos séculos XVII e XVIII". Observemse as expressões usadas na descrição e caracterização dos lugares, no papel que desempenham: o caráter da vida brasileira, a deliciosa capelinha do padre Faria e $o$ velho caráter de seus monumentos, que revelam uma percepção singular, capaz de apreender a "alma" dos monumentos, de respeitá-los. É possível atribuir à voz que enuncia, mais uma vez, um tom firme e assertivo, mas não duro, haja vista o efeito de doçura e carinho que a expressão deliciosa capelinha provoca.

No fragmento abaixo, de Velhas igrejas, o cronista também discorre sobre cidades históricas.

(5) Apesar de vir da Bahia, tão rica de monumentos e tradições de nosso passado, Olinda produziu em mim uma emoção nunca dantes sentida. Na Bahia fica-se um pouco vexado de parar no meio do tumulto das ruas para contemplar a frente de algum velho sobrado. Em Olinda há o silêncio e a tranquilidade que favorecem os passos perdidos dos que se comprazem nessa contemplação do passado e dos seus vestígios impregnados de tão nobre melancolia (Velhas igrejas. Bandeira, 2006, p. 69).

Nesse trecho, a comparação entre Bahia e Olinda é feita em um tom levemente triste e melancólico. A atribuição desse tom decorre não apenas da leitura da crônica (sobretudo a última passagem), mas também da imagem que o intérprete tem do autor, o ethos pré-discursivo que, como vimos, atribui ao autor traços ligados a sofrimento e à doença. Para fazer referência à primeira cidade, a como se sentiu ao parar em frente aos sobrados para contemplá-los, o cronista fala carinhosamente como um baiano: vexado. É interessante observar como o fragmento ilustra a distinção entre ethos dito e ethos mostrado. Em nenhum momento o autor diz que é um observador atento, mas a leitura mostra essa qualidade. Em relação à caracterização do que encontra em Olinda, ressalte-se a expressão tão nobre melancolia presente no último enunciado, mais um índice no qual se apoia o intérprete para atribuir um ethos digno e magnânimo à voz que enuncia. Desse modo, o autor atesta o que diz, a saber, o respeito à grandeza de monumentos e tradições de nosso passado, por meio de seu tom.

(6) $\mathrm{O}$ encanto do Recife não aparece à primeira vista. O Recife não é uma cidade oferecida $\mathrm{e}$ só se entrega depois de longa intimidade. Se não fosse muito esquisito comparar cidades com mulheres, eu diria que o Recife tem o físico, a psicologia, a graça arisca e seca, reservada e difícil de certas mulheres magras, morenas e tímidas. Porque, não repararam que há cidades que são o contrário disso? Cidades gordas, namoradeiras, gozadonas? O Rio, por exemplo. Belém do Pará, São Luís do Maranhão são cidades gordas. A Bahia é gordíssima. São Paulo é enxuta. Mas Fortaleza e o Recife são magras. Essa magreza é sensível em tudo no Recife. A vida comercial da cidade estendeu-se a comprido da avenida Marquês de Olinda até o fim da rua da Imperatriz. Os sobrados são magros e magros todos os detalhes arquitetônicos. Mesmo nas velhas casas solarengas do bairro da Madalena há não sei quê de seco, de sóbrio, de abstinente - de magro em suma (Um grande artista pernambucano. Bandeira, 2006, p. 105).

É interessante observar como é feita a descrição das cidades, atribuem-se a elas características humanas, o autor as compara a mulheres. Para se referir ao Recife, cidade onde nasceu e passou parte da infância, o cronista diz que ela tem "a graça arisca e seca, reservada e difícil de certas mulheres magras, morenas e 
tímidas" Ao Recife e sua magreza opõem-se as cidades "gordas, namoradeiras, gozadonas", como o Rio, São Luís do Maranhão, Belém do Pará. A comparação não é valorativa, isto é, não há ascendência das cidades magras sobre as gordas ou vice-versa, cada "tipo" tem sua graça e valor. Em termos de ethos, podemos dizer que se trata de um ethos híbrido uma vez que é possível atribuir um tom leve, bemhumorado, de um bom sujeito, nas passagens nas quais é feita a caracterização das cidades e também um tom mais sério, na última passagem, quando se destacam os velhos sobrados de Olinda, na sequência de adjetivos (insólitos) atribuídos a eles: seco, sóbrio, abstinente, magro.

Vimos que Maingueneau considera ser possível associar ao fiador do texto um caráter e uma corporalidade, traços que o intérprete identifica levando em conta representações e estereótipos que a enunciação pode reforçar ou não. A leitura do trecho apresentado, podemos dizer, implica um tom que remete a um corpo elegante, bem-apessoado, sereno, educado. Levando em conta a descrição das cidades, como são apresentadas, o intérprete é levado a avaliar de forma positiva o autor (a caracterização só pode ter sido feita por um observador atento e arguto).

\subsection{Falando de pessoas e de obras}

Manuel Bandeira escreveu inúmeras crônicas tratando de pessoas conhecidas, artistas ou não. Chegou a ter uma coluna, "Impressões literárias", no Diário de Notícias, em que resenhava livros lançados, muitos de amigos do cronista. Também escrevia sobre música, pintura e escultura, prestigiando salões de arte e exposições. Nesta seção, apresentamos trechos de textos que dão uma pequena ideia do trabalho a que se dedicava Bandeira.

(7) Anteontem dei um pulo à casa de Portinari para ver as telas que ele vai mandar à bienal do México. O que há de novo nelas são as cores. De vez em quando Portinari se vira para um certo setor de sua paleta, onde se esbalda. Os temas são os mesmos: músicos, espantalhos, enterros, casamentos, meninos brincando (há entre estes um de bodoque, que é uma de suas obras primas). Nenhuma figura bonita. Ao contrário, todas são pungentemente feias, que é assim que Portinari vê ou se lembra da nossa população do interior ou das favelas - subnutrida, raquítica, opilada, escanifrada. Toda essa miséria esplende, porém, em tonalidades ricas, em jogos de volume de fazer inveja aos mais ousados concretistas (Cores da miséria. Bandeira, 2015, p. 81).

$\mathrm{O}$ cronista relata aos leitores o andamento da pintura que Portinari iria apresentar na bienal do México. O trecho é bastante expressivo, tem marcas do inscritor Bandeira, como a seleção das palavras para nomear ações (se vira para um certo setor de sua paleta, onde se esbalda) e caracterizar pessoas. A expressão pungentemente feias, usada para caracterizar as figuras retratadas pelo pintor, desvela uma aproximação do autor em relação a essas figuras esquecidas, sendo que o emprego do embreador nosso inclui o leitor no efeito de empatia que o trecho permite construir. É possível atribuir ao fiador do trecho (sobretudo no último fragmento) uma voz de denúncia das condições precárias de vida "da nossa população". Observe-se a sequência subnutrida, raquítica, opilada, escanifrada, que supõe uma voz quase que revoltada, inconformada com a situação das figuras retratadas. 
Maingueneau, em seu último trabalho sobre ethos (2016), afirma que este tem diferentes dimensões, uma delas a dimensão ideológica, que se refere a posicionamentos no interior de campos discursivos. Como se sabe, o posicionamento modernista é marcado pela defesa do Brasil, de seu povo, de sua língua e cultura, que deveriam ser retratados sem recalques. Assim, tanto Portinari, que retrata o povo sofrido, quanto o autor da crônica, que fala sobre "toda essa miséria", o fazem por conta da inscrição nesse posicionamento. A dimensão ideológica do ethos pode ser apreendida pelo tom engajado que emerge da leitura do trecho.

(8) Mário de Andrade, o grande poeta paulista, acaba de dar o seu primeiro romance, intitulado Amar, verbo intransitivo, romance que ele ironicamente inculca de idílio imitado de Paula e Virgílio, mas que na realidade é obra da mais forte e peculiar originalidade, obra macanuda, que possui a gente como o Dédalo de Joyce, cuja comparação se impõe. Não que tenha entre as duas nenhum ponto de contato, senão este: ambas são profundamente nacionais - brasileira, gostosissimamente brasileira a de Mário; irlandesa a do outro; todas duas, porém, revolvendo no leitor a mais reflexiva, a mais comovida humanidade, e portanto - obras universais (Amar, verbo intransitivo. Bandeira, 2008, p. 110).

Nas crônicas de Manuel Bandeira, o nome Mário de Andrade se destaca, tanto devido ao número de textos dedicados a ele (cinco), quanto às inúmeras referências que podem ser encontradas na leitura das crônicas. No fragmento apresentado, a caracterização do romance e o efeito que sua leitura provoca são feitos, mais uma vez, por meio de vocábulos e expressões "fortes", nos quais se apoia o intérprete para atribuir um ethos ao autor. Assim, obra da mais forte e peculiar originalidade, obra macanuda revelam a avaliação do cronista sobre a obra (universal como a de Joyce), e também remetem a um fiador firme e seguro, que sabe do que está falando, tem bagagem para isso. Na sequência, aparecem os qualificadores nacional, brasileira, gostosissimamente brasileira, que seria o ápice do elogio, seguidos das expressões "a mais reflexiva", "a mais comovida humanidade", que seriam revolvidas no leitor. Nessa última passagem, é possível apreender um tom emotivo, carinhoso para com o amigo. Aqui também, como no trecho anterior, a dimensão ideológica do ethos se faz presente. Das qualidades do livro, as avaliadas de forma mais positiva são aquelas referentes a seu caráter nacionalista: a obra é gostosissimamente brasileira sem deixar de ser universal. Em relação ao mundo ético, aquele habitado pelo fiador do texto e incorporado pelo leitor, trata-se de um mundo de sujeitos honrados, dignos e generosos. Vejamos o fragmento de outra crônica que fala sobre Mário de Andrade.

(9) O meu amigo Mário de Andrade sofre hoje o mesmo vexame por que já passei em 1936, a saber, completa cinquenta anos de idade. E não encontro palavras melhores para definir vida tão bem vivida que as do conselheiro Acácio: "bem preenchida e digna". (...) Como poeta, sendo capaz de extrema depuração dos Poemas da negra e dos Poemas da amiga, encheu muitos outros, como por exemplo o magnífico "Noturno de Belo Horizonte", de tiradas polêmicas, patriotismo, eloquência, um verde-amarelo brabo (Meu amigo Mário de Andrade. Bandeira, 2015, p. 363-364). 
Nas palavras do conselheiro Acácio está aquela que aparece com frequência nas descrições avaliativas do cronista: digna. A seleção da palavra, e sua recorrência nos textos, mostra que se trata de um sujeito que prioriza traços do caráter das pessoas, o que elas teriam de elevado, honesto, humano. A crônica é uma homenagem a Mário de Andrade, sendo que no trecho focalizam-se dois livros de poesia do escritor paulista. Como no trecho anterior, são muitos os elogios, sobressaindo os aspectos ligados ao nacionalismo dos modernistas. A expressão verde-amarelo brabo remete a um fiador que fala de forma direta e franca, uma voz amigável e "modernista".

Abaixo transcrevemos um fragmento de uma crônica que trata de uma exposição de Lasar Segall:

(10) Toda a série gráfica tem essa concisão de épura de onde toda a ideia de virtuosidade profissional está excluída. Todavia nenhuma secura, e o sentimento domina sempre imperiosamente o assunto. Sinto não poder fornecer aos leitores cópia de certa água-forte onde só aparece a parte mais alta de um transatlântico: uma ponta de mastro, as três enormes chaminés, e a cabeça, só a cabeça, de um marinheiro. A composição é de uma força empolgante. Sente-se por exclusão a agitação dramática do resumo de humanidade que viaja embaixo desde a primeira até a terceira classe. Sente-se a solidão oceânica, a indiferença cósmica. Sente-se sobretudo a força e a dignidade da triste da figura. Aquele marinheiro está evidentemente perto de Deus ou da revolução (A exposição de Lasar Segall. Bandeira, 2009, p. 120).

É interessante observar como o cronista procura dar ao leitor uma imagem exata de uma das obras que contemplou. Na descrição, os traços mais marcantes, a avaliação que faz da figura: "a composição é de uma força empolgante". As sensações que tal contemplação provoca são fortes e "contaminam" o leitor, o esforço do cronista valeu a pena. O trecho é repleto de expressões fortes, carregadas de lirismo: agitação dramática do resumo da humanidade, solidão oceânica, indiferença cósmica, a força e a dignidade da triste figura, nessa última a ocorrência de dignidade, mais uma vez, revela um olhar diferenciado, um olhar que apreende a "alma", o essencial. O último enunciado surpreende ao colocar lado a lado as palavras Deus e revolução. O ou indicaria exclusão ou inclusão? De qualquer maneira, pode-se atribuir um ethos franco e também elevado a essa voz.

Vejamos o último trecho dessa seção. Trata-se de uma das crônicas que Bandeira escreveu falando sobre os meninos da rua onde morou no morro do Curvelo:

(11) No entanto, não lhe posso guardar rancor, porque se lhe digo: "Lenine, você é um grande malandro! Não é?", ele me olha meio sério, meio rindo, com um ar tão meigo, tão lindo, tão cândido, que é de fazer inveja ao primeiro team dos anjos de Nosso Senhor (Lenine. Bandeira, 2008, p. 181).

Mesmo depois da travessura, o menino é retratado de forma meiga e carinhosa. Ao autor, o intérprete atribui uma voz doce, protetora, voz que incorpora, podendo, assim, aceder ao mundo ético de pessoas sensíveis e humanas, de pessoas de bem Ressalte-se a expressão "primeiro team dos anjos de Nosso Senhor" que reforça a sensibilidade com que é traçada a figura de Lenine. A expressão pode ser tomada 
como um índice no qual se apoia o intérprete para atribuir um ethos carinhoso ao fiador do texto.

Apresentamos abaixo um quadro que reúne mais exemplos de vocábulos e expressões nos quais o intérprete pode se apoiar para atribuir um ethos forte, digno e carinhoso ao fiador. Do lado esquerdo, o elemento que é objeto de apreciação e, do direito, a avaliação a ele atribuída.

\begin{tabular}{|c|c|}
\hline Elemento apreciado & Avaliação \\
\hline $\begin{array}{l}\text { o meu amigo Mário de } \\
\text { Andrade }\end{array}$ & homem de bem e entendido de verdade \\
\hline um livro & simples, puro, honesto \\
\hline Sérgio & o anticafajeste por excelência \\
\hline A Belém de 1929 & tão tranquilazinha e amorável \\
\hline Jaime Ovalle & personalidade federativamente brasileira \\
\hline Antigo sobrado & robusta dignidade \\
\hline traço & forte, áspero, duro \\
\hline palmeira & exemplo de retidão moral \\
\hline Obra de arquiteto & $\begin{array}{l}\text { de uma saúde, de uma robustez, de uma } \\
\text { dignidade }\end{array}$ \\
\hline Capelinha do padre Faria & tão ingênua e tão comovente \\
\hline
\end{tabular}

O quadro mostra certos vocábulos e expressões com função avaliativa que remetem a uma voz a que podem ser associados os traços, caráter, dignidade, honestidade. Além desses, apreende-se, em certos momentos, um tom doce e carinhoso (tão tranquilazinha e amorável). A dimensão ideológica do ethos também pode ser percebida, por exemplo, na expressão personalidade federativamente brasileira, que remete ao posicionamento modernista assumido pelo autorcronista. Dessa forma, podemos dizer que o mundo ético a que dá acesso a voz que enuncia nas crônicas, a voz que é incorporada pelo intérprete, é o mundo ético das pessoas de bem.

\section{CONSIDERAÇÕES FINAIS}

Neste artigo, procuramos explorar aspectos ligados à construção do ethos por parte do intérprete tomando para objeto de análise crônicas de Manuel Bandeira. Partindo do quadro teórico proposto por Maingueneau, observamos indícios nos quais o intérprete poderia se apoiar para elaborar tal construção. Vimos que o local privilegiado nas crônicas são palavras e expressões descritivo-avaliativas usadas para falar de si, de objetos (construções, obras) e de pessoas próximas ao cronista. Pudemos perceber a recorrência de certos predicados, como "honesto", "de caráter" e "digno", que permitem ao intérprete associar ao autor esses mesmos 
traços, ligá-lo a um mundo ético habitado por pessoas de bem, mundo incorporado pelo intérprete.

\section{REFERÊNCIAS}

BANDEIRA, Manuel. Manuel Bandeira. Poesia completa e prosa. Volume único. Rio de Janeiro: Nova Aguilar, 1985.

BANDEIRA, Manuel. Crônicas da província do Brasil. São Paulo: Cosacnaify, 2006.

BANDEIRA, Manuel. Crônicas Inéditas 1 (1920-1931). São Paulo: Cosacnaify, 2008.

BANDEIRA, Manuel. Crônicas Inéditas 2 (1930-1944). São Paulo: Cosacnaify, 2009.

BANDEIRA, Manuel. Flauta de papel. Rio de Janeiro: editora Global, 2014.

BANDEIRA, Manuel. Andorinha, andorinha. Organização de Carlos Drummond de Andrade. 4. ed. São Paulo: Global, 2015.

CAVALCANTI, J. R.; REZENDE, B. R. Reflexões sobre a construção da identidade do professor de língua portuguesa. In: BARBOSA, J. B.; SIMÕES, R. Formação de professores na educação básica. Campinas, Mercado de Letras, 2017.

MAINGUENEAU, D. Gênese dos discursos. Trad. Sírio Possenti. Curitiba: Criar edições, 2000.

MAINGUENEAU, D. O discurso literário. Trad. Adail Sobral. São Paulo: Contexto, 2006a.

MAIGUEnEAU, D. Cenas da Enunciação. Org. Trad. Sírio Possenti e M. Cecília Pérez de Souza-eSilva. Curitiba: Criar edições, 2006 b.

MAINGUENEAU, D. Não há autor sem imagem. Trad. Adail Sobral. In: Doze conceitos em Análise do Discurso. São Paulo, Parábola Editorial, 2010.

MAINGUENEAU, D. Retorno crítico sobre o ethos. In: BARONAS, R. L.; MESTI, C. P.; CARREON, R. (Orgs.). Análise do Discurso: entorno da problemática do ethos, do politico e de discursos constituintes. Campinas: Pontes editores, 2016.

Recebido: $24 / 03 / 2019$

Aceito: 20/05/2019

Publicado: 20/08/2019 